\title{
Sistemas de direção e práticas de gestão governamental em secretarias estaduais de Saúde*
}

\author{
Márcia Lotufo** \\ Alcides Silva de Miranda***
}

SUMÁRIO: 1. Introdução; 2. Aspectos metodológicos; 3. Resultados; 4. Discussão; 5. Conclusão.

SUMMARY : 1. Introduction; 2. Methodology aspects; 3. Results; 4. Discussion; 5. Conclusion.

Palavras-chave: gestão em saúde; políticas; planejamento e administração em saúde; governo estadual; sistemas de apoio a decisões administrativas; estudos de casos organizacionais.

KEY WORDS: health management; healthcare policy; healthcare planning and management; state government; support systems for management decision making; organizational case studies.

Este artigo trata dos questionamentos em relação à baixa capacidade dos governos para a formulação e implementação de políticas públicas, consi-

\footnotetext{
* Artigo recebido em out. 2006 e aceito em maio 2007. Os autores agradecem aos dirigentes do Departamento de Apoio à Descentralização da Secretaria Executiva do Ministério da Saúde do Brasil (DAD/SE/MS) e da Organização Pan-Americana de Saúde (Opas), representação Brasil, pela iniciativa institucional e apoio financeiro para a realização do estudo, no período de 2004 a 2005.

** Doutora em saúde pública (ISC/UFBA), professora adjunta do Instituto de Saúde Coletiva da Universidade Federal do Mato Grosso (ISC/UFMT), consultora do Departamento de Apoio à Descentralização, Secretaria Executiva do Ministério da Saúde (DAD/SE/MS). Endereço: Av. Historiador Rubens de Mendonça, 156/302 - CEP 78050-000, Cuiabá, MT, Brasil. E-mail: mflotufo@terra.com.br.

*** Doutor em saúde pública (ISC/UFBA), professor adjunto do Departamento de Saúde Comunitária da Universidade Federal do Ceará (DSC/UFC), consultor do Departamento de Apoio à Descentralização da Secretaria Executiva do Ministério da Saúde (DAD/SE/MS). Endereço: Rua Barão de Lucena, 101 - CEP 60831-250, Fortaleza, CE, Brasil. E-mail: alcides_miranda@uol.com.br.
} 
derando particularmente alguns casos de gestão governamental em secretarias estaduais de saúde, sob a ótica de seus dirigentes. Trata-se de um estudo de casos múltiplos, 12 secretarias estaduais de Saúde, com níveis de análise imbricados. O método adotado foi a "análise de conteúdo" de discursos proferidos por dirigentes governamentais do setor saúde, acerca de seus modos e práticas de gestão, destacando os processos de formulação de políticas, tomada de decisões e implementação de programas. As evidências referem-se às características dos gestores e da gestão no âmbito estadual de governo, denotando-se algumas dificuldades e lacunas nos processos de formulação de políticas, no uso de tecnologias de planejamento e programação, na conformação dos sistemas de direção estratégica e na implementação das políticas governamentais de saúde, além de investimentos para a qualificação das práticas de gestão setorial, com gradual incremento na capacidade dos governos estaduais para a condução e implementação de suas políticas.

\section{Management systems and practices in state departments of health}

This article deals with issues concerning the poor capability of governments in planning and implementing public policies and considers particularly some cases of government management inside state departments of health, according to their own managers. It is also an organizational case study of 12 state departments of health with intricate levels of analysis. The study adopted the 'content analysis' method, considering statements of public managers of the healthcare sector in which they pointed out their managerial ways and practices, as well as their policy-making, decision-making, and program implementation processes. The main subjects highlighted by the reports refer to the characteristics of both managers and management within the state government. They also indicate some difficulties and gaps in policymaking processes, in the use of planning and programming technologies, in the configuration of strategic management systems, and in the implementation of public healthcare policies. On the other hand there have been investments to improve management qualification, as well as a gradual increase in the capability of state governments in carrying out and implementing their policies.

\section{Introdução}

Nas últimas décadas, muitos estudiosos das políticas governamentais na América Latina têm ressaltado e propagado a constatação sobre a baixa capacidade dos governos para a implementação de políticas públicas. E, também, sobre a conseqüente necessidade de seu incremento e qualificação, a partir do 
redimensionamento das estratégias de governo, da reestruturação dos modos e meios de interlocução e administração dos conflitos de interesses, de mecanismos de responsabilização pública dos governantes, de uma melhor inserção do Estado na sociedade (Reis, 1994; Matus 1997; Catalá, 1998).

No Brasil, desde o início da década de 1990, diversas iniciativas e medidas de reformas administrativas têm sido implantadas nas três esferas governamentais, com o propósito anunciado de aumentar a eficiência no uso de recursos fiscais e melhorar a capacidade de governo (Abrucio, 2005).

Alguns modelos de gestão governamental têm sido adotados para orientar as diversas iniciativas de reformas administrativas em curso, com tendência hegemônica daqueles que operam com políticas e estratégias institucionais de racionalização estritamente sistêmica, reguladas por uma logística de natureza preponderantemente econômica e pautadas por uma agenda de ajustes fiscais, estruturais, funcionais etc. (Fiori, 2001). Nessa tendência, uma das principais variáveis a ser controlada é o tensionamento estabelecido entre as diversas demandas e a capacidade de respostas governamentais eficientes e eficazes, nos termos do mercado político (Wittman, 1989); tendo em vista a necessidade de preservação de uma dinâmica sistêmica estável e sustentável, com regulação permanente para o constante tensionamento entre os sistemas de representação de interesses e de execução das políticas públicas (Offe, 1994).

Essa tendência de modelagem para as reformas administrativas está mais orientada para o incremento da capacidade gerencial de governo; para a instituição de sistemas de condução e regulação, com direcionalidade sistêmica intrínseca e racionalidade teleológica. Um entorno logístico em que a capacidade governamental para a implementação de políticas públicas é mais valorizada na medida em que produza um superávit na equação entre custos orçamentários e benefícios eleitorais.

É interessante observar, em princípio e na prática, como a tendência hegemônica de racionalização gerencial para as reformas administrativas de governo pode ser (in) congruente ou (contra)producente para com a direcionalidade constitucional e normativa estabelecida para as políticas públicas em determinados setores governamentais, como o da saúde. Diretrizes normativas estabelecidas para as políticas públicas de saúde, como aquelas de descentralização política e administrativa, podem adquirir conotações diversas, dependendo das estratégias administrativas e programáticas adotadas efetivamente.

No Brasil, particularmente o setor governamental de saúde tem sido palco de importantes reformas institucionais. Os movimentos de compartilhamento de responsabilidades federativas e de descentralização das prerrogativas e competências institucionais entre as esferas governamentais têm produzido 
experiências singulares, onde são externadas contradições primordiais entre as premissas constitucionais e normativas estabelecidas, as alternativas e opções de direcionalidade institucional, as condições de governabilidade e a capacidade efetiva dos governos de implementação das políticas e estratégias adotadas.

No caso do Sistema Único de Saúde (SUS), além do desenvolvimento de uma logística organizacional própria e de tecnologias complexas baseadas nos princípios e diretrizes constitucionais (universalidade, integralidade, eqüidade, descentralização, participação popular a partir de instâncias de "controle social"), existe a necessidade de mediações políticas permanentes entre os gestores governamentais do setor. Mediações constituídas sob a égide do novo pacto federativo, que estabelece uma equivalência de prerrogativas de poder decisório (apesar da assimetria no domínio de recursos e capitais políticos, técnicos e administrativos) e uma interdependência de margens de autonomia institucional.

O propósito primordial da gestão em saúde é a produção de decisões, que desencadeia o processo de intermediação e implementação das políticas. Há muita complexidade e subjetividade envolvidas nesses processos de gestão. Os sistemas de direção, assim como o processo e os arranjos para a tomada de decisões, envolvem motivações, interesses, racionalidades imbricadas, intuição (e experiência intuitiva), conhecimentos, capacidades cognitivas, habilidades, qualidade estratégica, controle de capitais e recursos (tempo, informações, tecnologias, financiamento). Enfim, características e qualidades de pessoas (sujeitos, agentes, atores institucionais) e não somente de sistemas ou serviços (Miranda, 2005).

Em outros termos, os gestores públicos de saúde não podem ser meros agentes administrativos providos somente de uma racionalidade instrumental ou normativa, cujos comportamentos seriam regrados para a condução dos sistemas de saúde e serviços. Os gestores de saúde — formuladores e produtores de políticas e estratégias institucionais, dirigentes, comandantes, condutores e difusores dos sistemas institucionalizados de ação, conformam e constituem um campo de poder (Bourdieu, 1996) governamental em que ocorrem tensionamentos e mediações políticas contínuas e permanentes. Um campo de gestão permeado pelo poder institucional (político, técnico e administrativo), que opera sob a delegação e a tutela dos detentores de mandato executivo. As prerrogativas de poder e autonomia institucional desses gestores de saúde, e seu capital político, provêm de uma delegação indireta e de uma relação contratual (informal) de confiança com aqueles gestores públicos que detêm a autoridade política formal de um mandato eletivo. Portanto, o seu arbítrio é sancionado por quem lhes delega as prerrogativas de poder decisório e delimita as suas margens de autonomia política. 
Considerando-se a natureza complexa e o caráter polivalente (político, técnico, administrativo) da gestão governamental no âmbito do SUS, a idéia de capacidade de governo possui expressões variadas, tanto no atacado quanto no varejo. Pois tal capacidade governamental requer mediações políticas constantes, como a conformação e o exercício de distintas competências de ação, de caráter instrumental, estratégico, normativo, comunicativo. E, ainda, a aplicação de métodos e tecnologias de gestão compatíveis para a atuação em distintos âmbitos e tempos (curto, médio e longo prazos).

Alguns autores, como Matus (1994, 1996), sugerem conceitos logísticos mais apropriados para a análise sobre os modos e as práticas de gestão governamental. Matus $(1996,1997)$ refere-se a sistemas de direção estratégica, que deveriam servir de entorno logístico para as práticas de gestão governamental, tais como: a agenda dos dirigentes; o processamento tecnopolítico de problemas; o gabinete de crises; o planejamento estratégico; os orçamentos por programas; a cobrança e prestação de contas por desempenho; o monitoramento; a gerência por operações; o centro de treinamento de dirigentes. Considerando-se a aplicabilidade desses conceitos logísticos, em termos de contexto, condições, âmbitos e tempos das práticas de gestão governamental, alguns podem ser úteis e convenientes para avaliações normativas sobre a capacidade de governos para a implementação de suas políticas.

As questões relacionadas com a capacidade de governo estão em voga, cabe reconhecer, que elas também requerem investigações que possam produzir mais evidências empíricas sobre o assunto, além de análises e ensaios teóricos. Especialmente quando se trata de avaliações sobre experiências de governos subnacionais no setor de saúde, práticas governamentais ainda pouco exploradas em estudos empíricos.

Num dos estudos recentes sobre as características da gestão estadual, Abrucio (2005) constata avanços significativos na administração pública, como: maior regionalização administrativa dos governos estaduais; maior número de parcerias institucionais, sobretudo com municípios e ONGs; maior informatização de sistemas de informação; incremento no uso de planos plurianuais; maior utilização de novos modos de compras governamentais; políticas sociais mais participativas; inovações no relacionamento com os cidadãos; e maior preocupação com o trabalho em redes intergovernamentais. O estudo também aponta alguns problemas: fragilidade gerencial, desencontros com a política do macroplanejamento e falta de qualidade na chamada "ponta do sistema".

Mais estudos empíricos de avaliação sobre as características de gestão estadual em saúde e capacidade de implementação de políticas de saúde podem produzir novas evidências e servir para esclarecer aspectos relevantes 
sobre essas práticas. Podem confirmar e renegar hipóteses existentes ou produzir novos pressupostos. Além de subsidiar a reflexão e tomada de decisões pelos dirigentes de saúde.

\section{Aspectos metodológicos}

Trata-se de um estudo de casos múltiplos com níveis de análise imbricados (Yin, 1994) e abordagem metodológica predominantemente qualitativa, baseada no método de análise de conteúdo do tipo categorial e temática (Bardin, 1979).

Para a amostra intencional de casos foram selecionadas 12 secretarias estaduais de Saúde (SES) de todas as grandes regiões brasileiras, a partir dos seguintes critérios: maior tempo de atuação dos secretários nos cargos, representação dos mesmos na diretoria do Conselho de Secretários de Saúde (Conass), entidade nacional de representação de interesses dos dirigentes estaduais de saúde:

> Sul - Rio Grande do Sul e Santa Catarina;

v Sudeste - São Paulo, Rio de Janeiro e Minas Gerais;

v Centro-Oeste - Goiás e Mato Grosso;

v Nordeste - Bahia e Maranhão;

v Norte - Acre, Pará e Rondônia.

Os 12 secretários estaduais de Saúde foram entrevistados, e cada um indicou mais dois dirigentes, de sua respectiva SES, para participar do estudo. $O$ perfil dos 36 dirigentes entrevistados pode ser caracterizado da seguinte forma:

v predominância do sexo masculino (77,8\%);

- maioria vinda da área de saúde, sendo predominante a categoria médica (44\%), percentual mais significativo de médicos $(58,0 \%)$ quando considerados apenas os secretários de Estado;

จ a maioria cursou pós-graduação, principalmente nas áreas de saúde coletiva e administração;

、 a maior parte tem experiência de gestão pública e aproximadamente $10 \%$ têm experiência parlamentar;

จ $57 \%$ têm vínculo empregatício com a respectiva SES. 
As entrevistas semi-estruturadas (com roteiro de condução para as questões abertas), foram realizadas entre os meses de abril e maio de 2005, por cinco pesquisadores selecionados, contratados e treinados previamente.

Critérios de exaustividade, representatividade, homogeneidade, pertinência e recorrência de conteúdos temáticos definiram o limite das 36 entrevistas.

Os conteúdos temáticos abordados referem-se a uma categorização prévia (roteiro das entrevistas) e aos discursos de dirigentes sobre determinados aspectos da capacidade de governo. Os conteúdos temáticos prévios utilizados no roteiro de condução de entrevistas são relativos aos atributos da capacidade de governo e foram definidos a partir de um referencial teórico com prescrições sobre processos, sistemas e tecnologias de direção estratégica no âmbito governamental (Matus, 1996, 1997). Os aspectos evidenciados aludem aos processos de formulação de políticas e planejamento em saúde; programação interna; decisão; sistemas de direção estratégica; implementação; e inovações tecnológicas em gestão.

\section{Matriz de conteúdos temáticos}

\begin{tabular}{|ll|}
\hline Categoria operacional & Conteúdos temáticos \\
\hline Formulação de políticas & Atores mais referidos \\
& Características do processo de formulação \\
& Plano de saúde - vigência, bases para elaboração, vinculação do plano \\
& com outros externos \\
& Visão sobre a participação social \\
Processo decisório e & Características do processo \\
programação interna & Base para a decisão — referência e tipo de informação \\
& Programação na SES — lógica, instrumentos, visão de longo prazo, \\
& prioridades \\
Sistemas de direção & Agenda do dirigente - utilização do tempo e foco da atenção \\
estratégica & Manejo de crises \\
& Sistema de orçamento-programa \\
& Gerência por operações/coordenação estratégica \\
& Sistema de monitoramento \\
& Sistema de prestação de contas \\
& Política de formação em gestão \\
& Caracterização dos estados, caracterização dos dirigentes \\
& Qualidade em saúde \\
& Gestão — elementos facilitadores e obstáculos atuais, elementos \\
importantes para implementar políticas, inovações em gestão
\end{tabular}


A sistemática utilizada para o processamento e análise de conteúdo das informações coletadas seguiu a seqüência de:

v pré-análise - leitura flutuante das entrevistas transcritas, com classificação manual e ordenação prévia de enunciados intactos (sintagmas analíti$\cos )$;

จ constituição e exploração de um corpus de leitura intertextual - edição de enunciados significativos, de acordo com a pertinência, equivalência, exaustividade, representatividade e homogeneidade para com os temas previstos no roteiro ou surgidos espontaneamente no decorrer das entrevistas;

identificação de unidades de significado e de unidades de contexto - unidades textuais de palavras, linhas e parágrafos, oriundas dos enunciados escolhidos, e identificadas por conteúdos temáticos manifestos segundo reagrupamentos analógicos;

、 análise e explicação de significados evidenciados nos discursos, a partir de categorias de análise definidas por referência aos conteúdos temáticos e seus contextos factuais.

O estudo obedeceu às regras estabelecidas pela Resolução nº 196/96 do Conselho Nacional de Saúde, que fixa normas para os procedimentos éticos em pesquisas envolvendo seres humanos. Todos os entrevistados foram informados dos objetivos do estudo, e lhes foi assegurado o anonimato e a possibilidade de desistência.

\section{Resultados}

Os aspectos evidenciados na descrição dos resultados referem-se aos conteúdos temáticos identificados nos discursos dos dirigentes entrevistados, relacionados ao roteiro prévio (referencial normativo de sistemas de direção e condução) de temas sobre a capacidade de gestão em saúde no âmbito estadual de governo.

\section{Características mais gerais da organização administrativa}

Embora os estados selecionados possuam grande variação populacional e quantidade de municípios, observamos similaridades na organização administrativa das SES (Brasil, 2005). Todas operam com estruturas administrativas 
descentralizadas, regionais, microrregionais de saúde, que variam de acordo com características internas de cada unidade federativa (por exemplo, o Acre opera com três regiões de saúde, a Bahia com 30). Observamos, ainda, correspondências entre a delimitação intra-estadual das microrregiões e regiões de saúde para com a divisão geopolítica e administrativa preexistente.

Em pelo menos 9 (nove) dos estados pesquisados, foi constatada a existência de consórcios intermunicipais de saúde, e a maior parte deles está localizada nas regiões Sul e Sudeste, notadamente em Minas Gerais (com cerca de 70 consórcios intermunicipais).

Em 40\% dos estados estudados constatamos existência e funcionamento de instâncias de pactuação regional entre os secretários municipais de Saúde e os representantes regionais das SES, as chamadas comissões intergestores bipartites regionais.

De acordo com os entrevistados, denotamos que os avanços decorrentes do processo de descentralização intergovernamental do setor de saúde, ainda não permitiram uma mudança substancial na responsabilização dos municípios como os principais prestadores de serviços do SUS. Há proferimentos que apontam uma ambigüidade na atuação das SES, como coordenadoras dos sistemas estaduais de saúde e prestadoras de uma carga significativa de serviços, especialmente de internação em regiões metropolitanas.

\section{As noções de boa qualidade para a gestão governamental em saúde}

Para a maioria dos dirigentes entrevistados uma gestão estadual de boa qualidade é aquela focada nas necessidades do cidadão e que visa garantir a sua satisfação (oferta e qualidade de serviços, humanização, promoção de resultados e melhoria de indicadores). Existem também referências quanto ao processo de gestão propriamente dito, de que a qualidade estaria relacionada com: modernização gerencial, mudança cultural, qualificação de pessoal.

\section{Habilidades necessárias para uma boa gestão estadual em saúde}

Os proferimentos mais recorrentes sobre o tema das habilidades necessárias para uma boa atuação como dirigente do SUS no âmbito estadual, referiam-se à capacidade para motivar, liderar e conduzir pessoas num determinado sentido/visão, que deveria ser mais flexível e baseada em diálogo aberto, condução de processos e pessoas de "forma política", reconhecendo os conflitos e buscando construção de consensos num trabalho compartilhado. Ressaltou-se, 
também, a idéia de que um dirigente estadual de saúde deveria ter domínio de conhecimentos sobre os conteúdos da política de saúde, de saúde pública e de gestão. Também foram destacados valores e características individuais como transparência, ética, honestidade, fôlego, determinação, equilíbrio emocional, comprometimento e dedicação com o cidadão e os princípios do SUS.

\section{Formulação de políticas e planejamento em saúde}

As prioridades definidas nos processos de formulação das políticas estaduais de saúde estão referidas aos seguintes temas: descentralização e interiorização dos serviços e ações de saúde (principalpmente de média e alta complexidades), fortalecimento e ampliação dos serviços Atenção Básica e do programa Saúde da Família, melhoria da estrutura dos serviços de saúde, redução de indicadores de mortalidade infantil e materna.

Para a maior parte dos entrevistados, o processo de formulação das políticas está ligado principalmente ao Plano Estadual de Saúde. De um modo geral, ressaltamos que existe uma relação de coerência entre os planos estaduais de saúde e os planos de governo. Em pelo menos metade dos casos estudados, houve a referência de que os planos de saúde foram concebidos a partir de diretrizes dos planos de governo.

Os planos estaduais de saúde são, em sua maioria, formulados internamente nas SES, ainda que de forma colegiada ou, em poucos casos, de forma ascendente. Uma vez elaborados, os planos estaduais de saúde são geralmente encaminhados para apreciação e aprovação das instâncias formais de decisão no âmbito estadual do SUS: comissões intergestores bipartites e conselhos estaduais de saúde.

Os dirigentes identificaram fragilidades na participação social no decorrer do processo de formulação dos planos estaduais de saúde. Relataram que os conselhos estaduais de saúde atuam muito mais como instâncias de referendamento, do que propriamente de formulação de diretrizes para os planos.

Segundo os entrevistados, outros atores governamentais que influenciam ou participam da formulação das políticas estaduais do setor são os secretários municipais de Saúde, notadamente pela atuação destes nos conselhos estaduais de secretários municipais de Saúde (Cosems) que possuem representações formais nas instâncias de decisão.

Destacamos a importante influência do Ministério da Saúde na determinação de direcionalidade para as políticas estaduais de saúde, na medida em que muitas das prioridades definidas na esfera federal são consideradas na 
elaboração dos planos estaduais. Quanto à atuação do Ministério da Saúde no processo de formulação de políticas estaduais, existem alusões sobre dificuldade dele considerar as diferenças regionais, em razão de uma condução ministerial ainda excessivamente normativa, uniforme, rígida e burocrática, que trata de modo indistinto as situações complexas e condições diversas. Também existem referências acerca de dificuldades, da parte do MS, para avaliar e monitorar adequadamente a implementação das políticas estaduais de saúde. Também são relatadas queixas devido a uma atuação direta do MS junto aos municípios, sem a intermediação ou mesmo a ciência das secretarias estaduais de Saúde. Por outro lado, também é ressaltada a atuação positiva do MS no apoio e na cooperação intergovernamentais.

Os conteúdos temáticos citados como proeminentes na elaboração dos planos de saúde estaduais são: descentralização, interiorização e ampliação de serviços e ações de saúde, sobretudo de média e alta complexidades.

A maioria dos entrevistados não soube informar, com precisão, qual o método de planejamento adotado pelas SES. Entretanto, alguns fizeram referência a uma logística de planejamento estratégico e outros ao planejamento de "qualidade total".

Quando questionados sobre a perspectiva do planejamento de mais longo prazo ou abrangência, os entrevistados falaram freqüentemente do Plano Estadual de Saúde (tempo de gestão governamental). Foi registrada apenas uma citação que revela preocupação com temas mais abrangentes e contextuais (biotecnologia, bioinformática etc.), ainda que o mesmo entrevistado tenha afirmado não haver qualquer ação no sentido de discutir e planejar ações relacionadas com tal abrangência.

Ainda sobre o tema do planejamento, alguns dirigentes afirmaram não dar crédito à sua aplicabilidade no mundo real, caracterizando-o como um ritual simbólico e metódico necessário institucionalmente, mas incompatível com um cotidiano "que tem muito incêndio para apagar...". Outros dirigentes alegam inúmeras dificuldades para operacionalizar as ações planejadas ou programadas, embora em outros casos relatados, haja uma valorização da dimensão pedagógica do planejamento.

\section{Programação interna da SES}

A maior parte dos entrevistados afirmou que as suas respectivas SES realizam programações internas anuais. Os relatos descreveram grande heterogeneidade de instrumentos de programação utilizados e uma desintegração entre os mesmos. Alguns dirigentes relataram que, embora exista a progra- 
mação formal, utilizam cotidianamente outros meios para a condução de programas em curso.

\section{Processo de decisão}

No cotidiano das SES, o processo de decisão interno é considerado bastante participativo e ocorre freqüentemente em espaços colegiados. Em muitos casos, o secretário tem papel preponderante na tomada das decisões finais.

Quando perguntados sobre quais os critérios adotados para amparar ou subsidiar o processo de tomada de decisões, os dirigentes se referiram, pela ordem, à análise de situação; à experiência e intuição; às informações e opiniões técnicas; e à disponibilidade financeira.

Outro tema identificado diz respeito ao uso de subsídios para os processos de formulação de políticas e tomada de decisões, advindos dos sistemas de informações em saúde existentes. Há uma opinião recorrente de que o SUS produz muitas informações, mas que as mesmas encontram-se desconectadas e arquivadas em diferentes bancos de dados, dificultando sua disponibilidade e tornando-as de pouca utilidade no cotidiano da gestão.

\section{Sistemas de direção estratégica}

\section{A agenda dos dirigentes}

Todos os dirigentes entrevistados afirmaram cuidar pessoalmente da definição e atualização de suas agendas, em alguns casos com apoio de assistentes administrativos, geralmente as secretárias do gabinete.

No cotidiano da gestão governamental, os dirigentes das SES costumam usar o seu tempo de forma diversa, predominando as atividades de reuniões e despachos internos com o pessoal administrativo, além de outras atividades citadas com menor freqüência como: atendimento ao público externo, agenda política, viagens e visitas aos serviços de saúde.

\section{Utilização do tempo e focos da atenção}

Os entrevistados relataram que existe sempre uma "grande pressão" das demandas imediatas sobre as prioridades da SES e que essa pressão dificulta o enfoque em temas programados, de médio e longo prazos. Os dirigen- 
tes "tentam cumprir a agenda", mas trabalham "meio programado e meio no improviso".

Em todos os casos, há o relato de que os gabinetes dos dirigentes das SES realizam mais um trabalho de triagem de problemas ou demandas emergentes e imediatas. Na maioria das vezes, a seleção de problemas ou demandas acontece de "forma mais formal e burocrática", embora em algumas SESs as respectivas assessorias técnicas realizem algum processamento técnico dos mesmos.

Nos gabinetes dos secretários estaduais, geralmente são realizadas reuniões periódicas com a equipe dirigente para avaliação e definição de linhas de condução na gestão governamental. Em muitos casos, tais reuniões são realizadas nos diversos departamentos ou setores das SES.

\section{Condução de crises}

A maior parte dos entrevistados informou ter vivenciado algum momento ou situação de crise no decorrer do processo de gestão em análise. Foram consideradas as seguintes situações de crise: a repercussão de problemas de saúde da população, os problemas de gestão dos sistemas de serviços de saúde e os "problemas políticos".

Na maioria dos relatos, a condução de reações ou respostas institucionais ante as referidas situações de crise, ocorreu de forma centralizada e personalizada. Não houve nenhum relato que identificasse treinamentos prévios, rotinas, sistemáticas institucionais ou tecnologias específicas preparadas para a reação e condução dos dirigentes nas situações de crise.

\section{Sistemas de orçamentos por programas}

As propostas orçamentárias das SES, de uma maneira geral, são inicialmente elaboradas no âmbito interno e estão sob a responsabilidade dos técnicos ou assessores de planejamento.

Prevalece a preocupação com o cumprimento de tetos orçamentários, que são distribuídos entre as unidades orçamentárias governamentais e definidos, previamente, pelas secretarias de estado da Fazenda. Em poucos casos, há o relato de coerência ou integração entre os orçamentos previstos nos planos de saúde e os orçamentos definidos pelas secretarias estaduais de Fazenda.

Geralmente prepondera uma lógica incremental na elaboração das referidas peças orçamentárias, como sugerem as citações a seguir: "a gente traba- 
lha o orçamento em função do total que será disponibilizado para o Fundo Estadual de Saúde"; "não se observa estritamente aquilo que está planejado, vai mais dentro de um processo reativo daquilo que já foi executado nos exercícios anteriores, do que uma visão propriamente dita de futuro que possa a partir da peça orçamentária basilar as ações que estejam planejadas".

Os dirigentes entrevistados não teceram comentários mais precisos sobre os modos de execução orçamentária e financeira das SES, entretanto, alguns reclamaram do "excesso de processos exigidos pela burocracia", da falta de articulação entre os planos e a execução financeira, da morosidade da administração pública financeira, da ausência de métodos de trabalho.

Por parte de alguns dirigentes entrevistados, há o reconhecimento de uma dissociação ou diversidade de lógicas: "estamos falando de setores diferentes da secretaria, de profissionais com qualificações diferentes, com linguajar diferente, um é o linguajar orçamentário, financeiro, e o outro é o linguajar da política de saúde".

\section{Gerência por operações}

Não existem relatos sobre o gerenciamento sistemático e específico das operações planejadas e/ou programadas previamente. Os relatos mais recorrentes definem os modos de gerenciamento como "fragmentados, com um relativo isolamento entre as áreas, desarticulados e segmentados" que os dirigentes designam como "lógica das caixinhas".

\section{Sistemas de monitoramento, controle e avaliação}

A maioria dos dirigentes entrevistados afirmou fazer controle e avaliação das ações de saúde sob sua responsabilidade direta ou dos municípios, embora todos tenham reconhecido o tema como um "nó crítico" no processo de gestão no SUS estadual. Alguns consideraram os modos e práticas de controle e avaliação "frágeis, não sistemáticos e insuficientes".

As dificuldades dessa ordem foram imputadas a uma "questão cultural", pois alguns alegaram que tradicionalmente a administração pública no setor saúde não tem a prática de realizar avaliação dos planos, projetos e programas.

Há relatos de esforços de superação dessas dificuldades, a partir de iniciativas para a "modernização da administração pública", que vem exigindo dos governos estaduais o cumprimento de alguns quesitos obrigatórios, em termos de prestação de contas. 
Em alguns casos, o monitoramento das ações institucionais das SES ainda que deficiente, acontece em reuniões periódicas.

\section{Sistemas de prestação de contas}

Segundo a maior parte dos relatos, a prestação de contas das gestões estaduais ocorre de modo formal e regular (exercícios anuais), de acordo com as exigências normativas (Tribunal de Contas) ou legais. Por exemplo, o chamado "relatório de gestão", exigido legalmente, é um instrumento de prestação de contas muito citado nos relatos.

Muitos expressaram um juízo positivo sobre a importância dos "relatórios de gestão", outros consideram mera formalidade a ser cumprida pela organização.

Todos relataram que as suas respectivas SES possuem sistemas de prestação de contas, entretanto, consideraram que ainda predomina uma "lógica formal", em resposta às exigências legais e não propriamente a uma necessidade de publicizar e discutir com a sociedade os resultados da administração pública: "é muito mais uma prestação de contas na parte contábil e financeira, não tem uma prestação de contas das atividades, através de conselhos e assembléias, não funciona ainda como norma sistemática aqui na Secretaria de Saúde".

As SES apresentam os resultados de suas gestões mais freqüentemente aos conselhos estaduais de saúde e ao Tribunal de Contas do Estado, seguido dos órgãos internos dos respectivos governos estaduais. Em alguns poucos casos, existe a prestação de contas para as respectivas assembléias legislativas, uma exigência legal que nem sempre é cumprida.

\section{Formação de dirigentes}

Os entrevistados relataram que nas SES ainda são incipientes as propostas e iniciativas de formação de pessoal especificamente para o exercício da função de gerência e/ou gestão. Entretanto há uma clara preocupação desses dirigentes quanto à necessidade de qualificar os profissionais para essa função.

Segundo os relatos, os investimentos em qualificação de pessoal são considerados pontuais. Algumas SES buscam apoio externo para essa formação, principalmente de instituições universitárias, demandando a qualificação nas áreas de gestão hospitalar, auditoria, gestão de sistemas e de serviços de saúde.

Alguns dirigentes falaram sobre existência de centros formadores ou escolas de saúde pública atuando em seus estados, mas afirmaram que elas 
ainda têm uma capacidade limitada para dar conta dos enormes desafios de formação para o SUS no âmbito estadual.

\section{Implementação de políticas governamentais de saúde}

Como elementos ou atributos mais importantes para a implementação de políticas governamentais, foram citadas: existência de profissionais competentes, qualificados e comprometidos; firmeza de liderança e coordenação na condução dos planos de saúde; necessidade de boas relações intra e interinstitucionais com prestadores e conselhos estaduais de saúde (gestão participativa e compartilhada).

\section{Facilidades e dificuldades identificadas para o exercício da gestão governamental em saúde}

Entre os aspectos facilitadores reconhecidos nos processos de gestão nas SES, destacam-se: características e habilidades dos dirigentes (liderança, clareza de direção, compromisso com o plano, continuidade); o trabalho de equipe (comprometimento, apoio, comunicação); e as condições de governabilidade setorial (apoio que o secretário tem do governo do estado).

Quanto aos aspectos dificultadores referidos, podem ser citados: a burocracia; a falta de integração; a resistência ante as mudanças; a centralização; a ausência de planos de carreira e ascensão funcional; os salários baixos; os problemas de governabilidade (pressão e interferências externas); e os problemas de financiamento insuficiente.

\section{Inovações na gestão governamental em saúde}

Muitos dirigentes citaram um conjunto de projetos e programas iniciados por sua respectiva SES, como exemplos de inovações tecnológicas na gestão em saúde: mudanças no processo de trabalho; definição de novas atribuições funcionais; exercício de gestão compartilhada; novos métodos, técnicas e instrumentos de planejamento (instrumentos de programação e desenvolvimento de software nessa área e em controle); novas modalidades e mecanismos de repasse de recursos financeiros (premiações por resultados etc.); e novos modos de ordenação de fluxos administrativos. 


\section{Discussão}

A caracterização do perfil dos dirigentes entrevistados denota uma típica predominância masculina, com profissionais oriundos do campo da saúde. Em muitos casos, a autoridade simbólica outorgada pela profissão médica ainda prevalece como característica. Apesar da formação de pós-graduação em saúde pública, realizada por muitos dirigentes, a maior parte não possuía formação de pós-graduação específica na área de administração pública.

Observamos uma preocupação com o processo de descentralização da gestão administrativa das SES. Descentralização ancorada nos propósitos de apoio administrativo e cooperação técnica com os municípios, a partir das estruturas microrregionais das SES e com a mediação política permanente de colegiados intergestores regionalizados (as comissões bipartites regionais).

O processo de formulação de diretrizes políticas, técnicas e administrativas para a gestão governamental do setor está orientado pela legislação e normas sanitárias vigentes nacionalmente. O Plano Estadual de Saúde é entendido e valorizado como uma formalidade de síntese da direcionalidade política adotada pela gestão estadual, mas observamos um descrédito quanto à sua aplicabilidade real e utilidade cotidiana. Os descompassos assinalados entre a previsão de uso de recursos financeiros nos planos de saúde e a destinação efetiva de recursos dos planos orçamentários estaduais podem, em parte e hipoteticamente, explicar tal descrédito.

Os planos estaduais de saúde e os relatórios de gestão são relatos de formulações diretivas e prestação de contas, valorizados à medida que são exigidos formalmente e como referências simbólicas. Todos concordam com a necessidade de sua realização, mas muitos questionam sua utilidade como tecnologia de apoio ao processo cotidiano de gestão. Os métodos usuais de planejamento setorial tampouco foram reconhecidos ou citados pela maioria dos dirigentes entrevistados, o que reforça a hipótese sobre a sua pouca aplicabilidade. A direcionalidade para a condução política deriva mais das agendas de prioridades de governo em si e de forma não-sistemática, do que dos planos estaduais de saúde.

Não há evidências de que as SES trabalhem com a construção de cenários projetados para prazos mais longos. O que pode ser um complicador, dado o período de maturação de projetos no setor saúde e a necessidade de responsabilização dos governantes nas decisões de longo prazo, que têm maior impacto no futuro das sociedades (Dror, 2000).

A programação de atividades internas conforma uma cultura institucional mais consolidada, quando se trata da replicação dos programas normativos oriundos do Ministério da Saúde (organizados para grupos populacionais ou 
doenças, a exemplo de crianças, idosos, diabetes, tuberculose etc.). Quando se trata de programações próprias das SES, notadamente daquelas definidas a partir dos planos estaduais de saúde, revela-se uma dificuldade maior de aplicabilidade, em razão da sobrecarga de problemas emergentes e demandas não-programadas. $\mathrm{O}$ estudo identificou, além da insuficiência dos modos de processamento técnico e político dos problemas e demandas que sobrecarregam a agenda dos dirigentes, o predomínio da triagem de problemas realizada pelas chefias de gabinete.

O exercício da programação nas SES tem sido provocado pelas demandas oriundas das secretarias de Planejamento dos governos estaduais, pela exigência de elaboração dos planos plurianuais (PPA), além, é claro, do próprio Ministério da Saúde, em função dos instrumentos de programação (pactos) como documentos de transferência de recursos financeiros intergovernamentais. No processo de construção do SUS, vêm sendo adotados diversos instrumentos de gestão, que apresentam graus de adesão diferentes, em função da compreensão dos atores sociais e da complexidade dos instrumentos diante da capacidade de cada instituição em responder a essas demandas. Ainda que seja louvável o esforço para uma definição conjunta (intergovernamental) de arranjos organizacionais e de instrumentos normativos de gestão, os relatos sugeriram que tal processo ainda tem ocorrido de forma muito centralizada e, em alguns casos, sem considerar as diferenças regionais.

Os dirigentes se referiram ao aperfeiçoamento dos sistemas de programação das SES, mas observamos que ainda não é comum a utilização dos sistemas de orçamento e gerenciamento por programas. Não se trata de uma constatação exclusiva do setor de saúde, conforme aponta a radiografia das administrações públicas estaduais realizada pelo Conselho Nacional de Secretários de Administração (Abrucio, 2005).

Pelos depoimentos analisados, grande parte dos dirigentes não realiza nenhum processamento técnico ou político daqueles problemas não-programados, que são preponderantes e muitas vezes recorrentes. Apesar dessa constatação, denota-se maior valorização dos subsídios técnicos para o processo decisório dos dirigentes estaduais, concomitantemente com a análise sobre a disponibilidade de recursos orçamentários.

Os relatos sugerem que os dirigentes não têm investido em logísticas e tecnologias especializadas e apropriadas para a condução de crises. Tampouco na preparação e treinamento de pessoal para essa finalidade.

É evidente a constatação dos dirigentes acerca da insuficiência ou inadequação dos sistemas de monitoramento, controle e avaliação das medidas e ações governamentais, existentes tanto nas SES como no Ministério da 
Saúde, o que dificulta o processo de tomada de decisões e de condução de ajustes institucionais em tempo hábil, no curso das ações governamentais.

Segundo os dirigentes, a prestação de contas das SES, salvo os relatórios de gestão, possui um caráter restrito, burocrático (no sentido pejorativo do termo) e muito formal.

Os problemas de implementação não são resolvidos somente pela garantia de respeito aos regulamentos ou a partir de modos convencionais de gerenciamento administrativo. A prática gerencial em si já é uma fonte de complexos problemas que não resultam apenas de grandes desacordos e conflitos sobre valores, objetivos ou metodologias. O maior problema deriva da rotinização de atividades e de interações cotidianas, muitas vezes consideradas pouco importantes. Segundo Pressman e Wildavsky citados por Velarde (2004) "la implementación, en las mejores circunstancias, es excesivamente difícil".

Reconhecendo que no processo de gestão estejam envolvidos diversos fatores, muitos deles não abordados neste artigo, os sistemas de direção jogam um papel fundamental na implementação das políticas governamentais. Muitas vezes, essa dimensão não é tão valorizada como o momento de formulação e/ou desenho da política.

Por fim, a análise das iniciativas descritas como inovadoras, nos termos da gestão estadual em saúde, indica mais uma racionalização instrumental de práticas já existentes, do que propriamente inovações de estratégias programáticas ou administrativas.

\section{Conclusão}

Neste artigo é possível evidenciar alguns aspectos sobre a realidade organizacional e o processo de gestão governamental das SES de acordo com os pontos de vista dos seus atores governamentais. Convém destacar que tais questões, mesmo quando problematizadas e coincidentes com outros achados de estudos similares, são apresentadas na perspectiva da inovação, crescimento, consolidação e legitimação do SUS. Apesar das lacunas e dos problemas identificados, constatamos a existência de investimentos para a qualificação das práticas de gestão setorial, com um gradual incremento na capacidade dos governos estaduais para a condução e implementação de suas políticas.

A gestão governamental do SUS é essencialmente uma prática social de âmbito setorial, cujo valor de uso refere-se a uma intermediação (direção, comando, condução e comunicação) das políticas públicas de saúde. A direcionalidade das políticas de saúde, embora estabelecida em lei (funda- 
mentos ético-normativos e estratégias de horizonte), não isenta seus gestores de suas responsabilidades na (re)formulação criativa e na garantia da viabilização de um direito social de relevância pública, a partir de condução cotidiana em busca de sua factibilidade, sustentabilidade, responsividade e utilidade em condições reais.

\section{Referências bibliográficas}

ABRUCIO, Luiz F. Reforma do Estado no federalismo brasileiro: a situação das administrações públicas estaduais. Revista de Administração Pública, v. 39, n. 2, p. 401-420, 2005.

BARDIN, Laurence. Análise de conteúdo. Persona Edições 70, 1979.

BRASIL. Ministério da Saúde. Cadernos de Informações de Saúde (estaduais), jun. 2005. . Conselho Nacional de Saúde. Resolução no 196, de 10 de outubro de 1996. Brasília, 1996. Disponível em: <http://conselho.saude.gov.br/resolucoes/1996/Reso196.doc>.

BOURDIEU, Pierre. Razões práticas — sobre a teoria da ação. Campinas: Papirus, 1996.

CATALÁ, Joan P. Governabilidade democrática na América Latina no final do século XX. In: BRESSER-PEREIRA, Luiz Carlos; SPINK, Peter (Orgs.). Reforma do Estado e administração pública gerencial. 2. ed. Rio de Janeiro: FGV, 1998.

DROR, Yehezkel. Os grandes desafios da moderna gestão pública: trajetórias a seguir. In: ENCONTRO INA - INSTITUTO NACIONAL DE ADMINISTRAÇÃO, 2. Lisboa, mar. 2000. Anais... Lisboa, 2000.

FIORI, Luiz. O cosmopolitismo de cócoras. Revista Educação \& Sociedade, v. 77, n. 1, p. 11 27, 2001.

MATUS, Carlos. Sobre a teoria das macroorganizaciones. Santa Fé de Bogotá: Fondo Editorial Altadir, 1994.

. Adeus, senhor presidente. Governantes governados. São Paulo: Edições Fundap, 1996.

. Los 3 cinturones del gobierno. Venezuela: Caracas, Fondo Editorial Altadir, 1997.

MIRANDA, Alcides S. Proposição de escopo para a avaliação da gestão no Sistema Único de Saúde. Relatório final de consultoria prestada ao Ministério da Saúde, nov. 2005. ms. 
REIS, Fábio W. Governabilidade e instituição política In: VELLOSO, João P. Reis; ALBUQUERQUE, Roberto C. (Coords.). Governabilidade, sistema político e violência urbana. Rio de Janeiro: José Olympio, 1994.

OFFE, Claus. Capitalismo desorganizado. 2. ed. São Paulo: Brasiliense, 1994.

VELARDE, Juan Carlos C. Una mirada estratégica y gerencial de la implementación de los programas sociales. In: CONGRESO INTERNACIONAL DEL CLAD SOBRE LA REFORMA DEL ESTADO Y DE LA ADMINISTRACIÓN PÚBLICA, 9. Madrid, Espanha, 2-5 nov. 2004. Anais... p. 2-33, Madrid, Espanha, 2004.

WITTMAN, D. Why democracy produce efficient results. Journal of Political Economy, v. 97, n. 6, p. 1395-1403, 1989.

YIN, Robert. Case study research design and methods. 2. ed. California: Saye Publications, 1994.

\section{Site consultado}

$<$ www.consad.org.br>. 